\title{
UNICEF e a implementação da Iniciativa Global Pelas Crianças Fora da Escola no Brasil
}

\section{UNICEF and the implementation of the Global Initiative for the benefit of Children Out of School in Brazil}

Thalita Franciely de Melo Silva

Doutoranda em Ciência Política na Universidade Federal de Pernambuco (UFPE)

E-mail: thalita.fmelo@gmail.com

Thays Felipe David de Oliveira

Mestre em Antropologia na Universidade Federal da Paraíba (UFPB)

Email: thaysfelipe@gmail.com

Joel Martins Cavalcanti

Graduando em Relações Internacionais na Universidade Estadual da Paraíba (UEPB)

E-mail: joel_cavalcantixd@hotmail.com

Resumo: A crescente necessidade de garantir a efetivação dos direitos das crianças e dos adolescentes fez com que tais direitos fossem regulamentados em vários intrumentos internacionais e nacionais. No âmbito internacional, a importância desse tema pode ser observada na Convenção das Nações Unidas sobre os Direitos da Criança (1989) e na Declaração e nos Objetivos de Desenvolvimento do Milênio (2000). No âmbito nacional, convém mencionar que o Fundo das Nações Unidas para a Infância constituiu-se como ator fundamental para a aprovação do Estatuto da Criança e do Adolescente no Brasil (1990) bem como para a implementação do Programa de Erradicação do Trabalho Infantil (1992). Este artigo objetiva analisar a influência do Fundo das Nações Unidas para a Infância na construção de políticas públicas educacionais no Brasil, em especial a partir da implementação da Iniciativa Global pelas Crianças Fora da Escola, que tem como objetivo alcançar a educação primária universal no Brasil, conforme meta estabelecida na Declaração e nos Objetivos de Desenvolvimento do Milênio.

Palavras-Chave: Educação; Políticas Públicas; Desenvolvimento do Milênio; UNICEF.

Abstract: The growing need to ensure effectiveness of rights of children and adolescents made societies all over the world to regulate those rights in various international and national documents. Internationally, the importance of this matter can be seen in the United Nations Convention on the Rights of the Child (1989), in the United Nations Millennium Declaration and its Millennium Development Goals Summit (2000). At the national level, it must be mentioned that the United 
SILVA, Thalita F. de M.; OLIVEIRA, Thays F. D.; CAVALCANTI, Joel M. UNICEF $e$ a implementação da Iniciativa Global Pelas Crianças Fora da Escola no Brasil

Nations International Children's Emergency Fund (UNICEF) played a decisive role towards approval of the Children and Adolescents General Statute of Brazil (1990) and towards implementation of the programme for the eradication of child labour (1992). This article aims to analyze the influence of the UNICEF on elaborating public policies on education in Brazil, particularly considering the implementation of the Global Initiative for the benefit of Children Out of School, which has the objective of reaching the universal primary education in Brazil, according to the goal set in the United Nations Millennium Declaration and its Millennium Development Goals Summit.

Keywords: Education; Public Policies; The Millennium Development; UNICEF.

\section{Introdução}

A discussão que envolve políticas públicas tem ganhado destaque nos últimos anos, não existindo ainda, uma definição única sobre seu conceito. Oliveira (2010) afirma que, política pública uma palavra de origem grega, politikó, que representa a condição de participação da pessoa livre nas decisões dos assuntos da cidade e a palavra pública é de origem latina, que significa povo e do povo.

Mead (1995) define política pública como um campo dentro do estudo da política que analisa o governo à luz de grandes questões públicas. Nesse sentido, cabe destacar o trabalho de Teixeira (2002), que afirma que as políticas públicas objetivam solucionar as demandas, em especial, dos setores marginalizados e vulneráveis, visando ampliar a efetivação dos direitos da cidadania.

Nesse contexto, é importante mencionar que as políticas públicas educacionais, segundo o entendimento de Richit (2012), é caracterizada pelo conjunto de diretrizes que se destinam a estruturar, gerir e melhorar a educação brasileira em todos os níveis e modalidades de ensino, incluindo estrutura física, pedagógica, corpo docente e discente, programas educativos diversos etc.

Para compreender a formulação e implementação de políticas públicas educacionais brasileiras, essa pesquisa visa analisar a influência do Fundo das Nações Unidas para a Infância (UNICEF) na construção de políticas públicas no Brasil, em especial, a partir da implementação da Iniciativa Global pelas Crianças Fora da Escola, que tem como objetivo alcançar a educação primária universal no Brasil, conforme meta estabelecida na Declaração e nos Objetivos de

Revista Brasileira de Políticas Públicas e Internacionais, v.2, n.2, Dezembro/2017, pp. 152-167. 
SILVA, Thalita F. de M.; OLIVEIRA, Thays F. D.; CAVALCANTI, Joel M. UNICEF $e$ a implementação da Iniciativa Global Pelas Crianças Fora da Escola no Brasil

Desenvolvimento do Milênio no ano 2000, que foi substituída pelos Objetivos de Desenvolvimento Sustentável em 2016.

Cabe mencionar que, essa iniciativa é fruto da necessidade de garantir o acesso à educação em sua totalidade e em todas as faixas etárias pelas crianças e adolescentes brasileiros. Ademais, objetiva explanar sobre a importância do UNICEF na regulamentação de instrumentos de proteção internacional e nacional dos Direitos da Criança e do Adolescente.

Quanto aos objetivos, trata-se de uma pesquisa descritiva, que segundo Gil (1991), visa proporcionar maior familiaridade com o problema, tendo como objetivo principal, o aprimoramento de ideias ou a descoberta de intuições. Segundo Fernandes e Gomes (2003, p. 7), são utilizadas "quando não existe trabalho científico anterior, pois fundamentalmente se está buscando um conhecimento maior sobre o tema, uma vez que este não foi ainda objeto de pesquisa”. No que tange aos procedimentos, constitui-se como estudo de caso, uma vez que oestudo da particularidade e da complexidade de um caso singular, isto é, a implementação da Iniciativa Global pelas Crianças Fora da Escola, pode levar a compreender qual a influência que o Fundo das Nações Unidas para a Infância pode exercer num contexto específico.

O presente artigo está estruturado em quatro seções em que, na primeira é apresentado um breve panorama sobre as políticas públicas educacionais no Brasil. Na seção 2, será explanado sobre o UNICEF e os instrumentos de proteção internacional e nacional dos direitos da criança e do adolescente. Na seção 3, será analisado a influência do UNICEF na implementação da Iniciativa Global Pelas Crianças Fora da Escola no Brasil. Por fim, serão elencados os principais desafios à permanência da criança e do adolescente na escola no Brasil.

\section{Políticas Públicas Educacionais no Brasil: um breve panorama}

No que se refere às políticas públicas educacionais no Brasil, não há um referencial teórico consolidado quanto ao tema. Magda Santos (2012) afirma que para compreender o sentido que as atuais políticas públicas educacionais assumem na relação entre Estado e sociedade, é necessário resgatar o histórico acerca da própria formação social brasileira e da influência que exerce sobre as

Revista Brasileira de Políticas Públicas e Internacionais, v.2, n.2, Dezembro/2017, pp. 152-167. 
SILVA, Thalita F. de M.; OLIVEIRA, Thays F. D.; CAVALCANTI, Joel M. UNICEF $e$ a implementação da Iniciativa Global Pelas Crianças Fora da Escola no Brasil

políticas educacionais de cada época. Por isso, faz-se necessário fazer um breve panorama das políticas educacionais e como foram desenvolvidas em alguns períodos da história brasileira.

No período colonial do Brasil (1500-1815), a educação estava ligada predominantemente à catequização dos índios pelos jesuítas, que ensinavam a ler e escrever com atividades literárias e acadêmicas que eram praticadas pela corte portuguesa. Somente com a chegada da Família Real, em 1808, que algum progresso na área de educação pode ser visto, particularmente, com a criação da Biblioteca Real e o estabelecimento do ensino superior.

No período imperial brasileiro (1822-1889), avanços na educação brasileira foram realizados, em especial, com a elaboração da primeira Constituição Brasileira, em 25 de março de 1824, que instituiu o ensino primário gratuito ${ }^{1}$. Importantes transformações no cenário educacional brasileiro ocorreram a partir da década de 30, em especial, com a elaboração de uma nova Constituição, em 16 de julho de 1934. Freitag (1980) destaca que essa Constituição demonstrou a necessidade de elaboração de um Plano Nacional de Educação que coordenasse e supervisionasse as atividades de ensino em todos os níveis ${ }^{2}$.

Magda Santos (2012) destaca que, com a instauração da ditadura militar no Brasil (19641985), o sistema educacional brasileiro teve que se adequar às exigências dos organismos internacionais, em especial, as recomendações advindas do governo norteamericano. Shiroma et al. (2002) destaca que o período militar deixou fortes resquícios não satisfatórios na área de educação, pois nessa época foram diminuídos drasticamente os recursos, chegando à década de 80 com índices de $50 \%$ de crianças que repetiram ou foram excluídas ao longo da $1^{\text {a }}$ série do primeiro grau, $30 \%$ da população constituídos de analfabetos, 23\% de professores leigos e 30\% de crianças fora da escola.

Com o fim do período militar em 1985, um novo panorama na educação brasileira pode ser visto com a elaboração da Constituição Federal Brasileira de 1988. Na década de 90, as políticas públicas educacionais foram marcadas pela reforma educacional, em especial, com a criação da à

\footnotetext{
${ }^{1}$ Cunha Bueno, em 1822, apresentou um projeto para a divisão do ensino em três graus, sendo o primário e o secundário para as províncias e o superior para a União.

${ }^{2}$ Foi a partir dessa década que se percebeu um salto na regulamentação das políticas educacionais do país, com a criação de vários decretos, e em especial, pela Reforma Francisco Campos, que instituiu o Ministério dos Negócios da Educação e Saúde Pública. Porém, somente na década de 40, que um debate sobre a criação de uma Lei de Diretrizes e Bases da Educação tomou amplitude, culminando na Lei no 4.024 de 20 de dezembro de 1961.
}

Revista Brasileira de Políticas Públicas e Internacionais, v.2, n.2, Dezembro/2017, pp. 152-167. 
SILVA, Thalita F. de M.; OLIVEIRA, Thays F. D.; CAVALCANTI, Joel M. UNICEF $e$ a implementação da Iniciativa Global Pelas Crianças Fora da Escola no Brasil

Lei $n^{\circ}$ 9.394/96, conhecida como Lei de Diretrizes e Bases. Essa lei foi resultado do “debate democrático de diferentes setores da sociedade e expressava o desejo desses segmentos de que a educação fosse assumida como prioridade do Estado” (Peres \& Castanha, 2006, p. 236) .

A partir do ano 2000, as mudanças nas políticas públicas educacionais brasileiras incorporaram temas como a exclusão e a valoração da sociodiversidade. Destaca-se aqui, a Declaração e os Objetivos de Desenvolvimento do Milênio (ODM), adotados na Cúpula do Milênio no ano 2000, no qual definem objetivos a serem atingidos até o ano de 2015, e os Objetivos de Desenvolvimento Sustentável (ODS), adotados em 2016, que estipulam metas para serem atingidas até 2030, e serve para complementar e corroborar os ODM.

A educação é um direito universal e dever do Estado brasileiro garanti-lo a qualquer pessoa, com a efetivação de políticas públicas. Como visto, ao longo das décadas, as políticas públicas educacionais foram distintase condicionadas à realidade de cada época. Nesse sentido, destaca-se a importância do Fundo das Nações Unidas para a Infância na construção de políticas educacionais no Brasil.

\section{O Fundo das Nações Unidas para a Infância no Brasil e os instrumentos de proteção internacional e nacional dos Direitos da Criança e do Adolescente}

O UNICEF está presente no Brasil desde o ano de 1950, quando foi instalado o primeiro escritório na cidade de João Pessoa, no estado da Paraíba ${ }^{4}$. Nesse período, as iniciativas desse Fundo objetivavam melhorar as condições de saúde das crianças, por meio de lançamento de campanhas referentes à merenda escolar, à vacinação, à saúde, à educação, o aleitamento materno, etc.

\footnotetext{
${ }^{3}$ A LDB instituiu dentre outras matérias, o ensino fundamental, obrigatório e gratuito, inclusive para os que a ele não tiveram acesso na idade própria (Art. 4, Inciso I); A educação escolar composta da educação básica, formada pela educação infantil, ensino fundamental e ensino médio; e a educação superior (Art. 21).

${ }^{4}$ O UNICEF possui escritórios no Brasil nas cidades de Brasília, Belém, Fortaleza, Manaus, Recife, Rio de Janeiro, Salvador, São Luís, e São Paulo. É importante destacar que as regiões dessas cidades foram consideradas prioritárias na implementação de estratégias nacionais com o objetivo de promover a criação de políticas públicas locais referentes àinfância e a juventude
}

Revista Brasileira de Políticas Públicas e Internacionais, v.2, n.2, Dezembro/2017, pp. 152-167. 
SILVA, Thalita F. de M.; OLIVEIRA, Thays F. D.; CAVALCANTI, Joel M. UNICEF $e$ a implementação da Iniciativa Global Pelas Crianças Fora da Escola no Brasil

Já na década de 60, pode ser notada a preocupação do UNICEF com a problemática da educação. As palavras de Kramer (2003, p. 77) expressam que:

"durante a década de 60, o UNICEF e outras agências ligadas à ONU, como a UNESCO, ampliavam sua atuação em relação à infância e reconheciam ainda, a importância da 'educação como preparação para a vida'. [...] Aumentava a crença na importância de se preparar crianças e jovens para contribuírem mais tarde para o desenvolvimento de seus países”.

Essa preocupação é estendida para o cenário brasileiro. Para Medeiros (2011), na década de 70, as análises da situação da infância levaram ao reconhecimento de que eram necessárias políticas em favor da infância e da juventude, na qual deveriam integrar o planejamento econômico e social do país, com ênfase nos programas preventivos. O UNICEF influenciou, na década de 80, para que se aprovasse o artigo 227 da Constituição Federal ${ }^{5}$ e o Estatuto da Criança e do Adolescente no Brasil, possibilitando uma mudança nas leis referentes a essa temática. A incorporação do Artigo 227, da Constituição Federal diz que:

"É dever da família, da sociedade e do Estado assegurar à criança e ao adolescente, com absoluta prioridade, o direito à vida, à saúde, à alimentação, à educação, ao lazer, à profissionalização, à cultura, à dignidade, ao respeito, à liberdade e à convivência familiar e comunitária, além de colocá-los a salvo de toda forma de negligência, discriminação, exploração, violência, crueldade e opressão”.

O UNICEF foi um parceiro importante do governo brasileiro para a implantação do Programa de Erradicação do Trabalho Infantil (PETI), no ano de 1992, após ter divulgado divulgou inúmeras denúncias sobre o trabalho de crianças no Brasil, o que gerou a necessidade de criar políticas públicas que pudessem atender a demanda de crianças e adolescentes que estavam vivendo em estado de vida desumana (Silva \& Ramalho, 2012).

Outra conquista brasileira que teve apoio do UNICEF foi aprovação da Lei nº 9.534/97, que garantiu a gratuidade do Registro Civil e a primeira via de certidão de nascimento para todas as

\footnotetext{
${ }^{5}$ Promulgada em 05 de outubro de1988.
}

Revista Brasileira de Políticas Públicas e Internacionais, v.2, n.2, Dezembro/2017, pp. 152-167. 
SILVA, Thalita F. de M.; OLIVEIRA, Thays F. D.; CAVALCANTI, Joel M. UNICEF $e$ a implementação da Iniciativa Global Pelas Crianças Fora da Escola no Brasil

crianças. Além disso, esse Fundo atuou para que a Emenda Constitucional n ${ }^{0} 59$ fosse aprovada, tornando obrigatório o ensino dos 04 aos 17 anos de idade.

Para Gusmão (2010) a educação é um dos principais eixos de ação do UNICEF, que trabalha para que se tenha acesso universal à educação de qualidade, assegurando a permanência com aprendizagem do aluno e a conclusão da educação básica na idade certa. Essa autora ainda afirma que a educação com qualidade é um direito fundamental que deve ser ampliado e garantido. Nesse contexto, o UNICEF se rege pelo princípio da equidade, atuando com prioridade em regiões necessitadas e vulneráveis como o Sertão Nordestino, o Norte do Brasil e os grandes centros urbanos.

A crescente necessidade de garantir a efetivação dos direitos das crianças e dos adolescentes foram regulamentados em vários intrumentos internacionais e nacionais. No âmbito internacional, a importância desse tema pode ser observado na Declaração de Genebra dos Direitos da Criança (1924), na Declaração Universal sobre os Direitos do Homem (1948), na Declaração Universal dos Direitos da Criança (1959), no Pacto Internacional sobre Direitos Civis e Políticos (1966), no Pacto Internacional sobre Direitos Econômicos, Sociais e Culturais (1966) e o no Pacto de São José da Costa Rica (1969).

Destaca-se aqui, a Convenção das Nações Unidas sobre os Direitos da Criança, adotada na Assembleia Geral da ONU, em 20 de novembro de 1989, e oficializado como lei internacional no ano seguinte ${ }^{6}$. Essa Convenção é fruto inicialmente da ideia do Governo da Polônia durante a trigésima quarta sessão da Comissão dos Direitos do Homem das Nações Unidas, no ano 1978. A intenção era que essa Convenção fosse adotada no ano seguinte, 1979, no Ano Internacional da Criança, porém, foi criado um Grupo de Trabalho de Composição Ilimitada para discutir os direitos da criança. Esse Grupo de Trabalho era composto por vários países, organizações intergovernamentais e organizações não governamentais, que se reuniram nos anos de 1980, 1987, 1988 e 1989, sendo nesse último ano a adoção dessa Convenção

\footnotetext{
${ }^{6}$ Essa Convenção é fruto inicialmente da ideia do Governo da Polônia durante a trigésima quarta sessão da Comissão dos Direitos do Homem das Nações Unidas, no ano 1978. Essa Convenção foi ratificada por 193 países, somente os Estados Unidos e a Somália não ratificaram. O Brasil assinou a Convenção em 26 de janeiro de 1990 e foi ratificada pelo CongressoNacional em 14 de setembro de 1990. A Convenção foi o marco internacional na concepção de proteção social a infância e adolescência e que deu as bases para a Doutrina da proteção integral, que fundamentou o Estatuto da Criança e do Adolescente (ECA Lei no 8.069, de 13.07.1990).
}

Revista Brasileira de Políticas Públicas e Internacionais, v.2, n.2, Dezembro/2017, pp. 152-167. 
SILVA, Thalita F. de M.; OLIVEIRA, Thays F. D.; CAVALCANTI, Joel M. UNICEF e a implementação da Iniciativa Global Pelas Crianças Fora da Escola no Brasil

Albernaz Júnior e Ferreira (2011) ressaltam que essa Convenção tinha como objetivo, incentivar os países membros a implantarem o desenvolvimento pleno e harmônico da personalidade de suas crianças, favorecendo seu crescimento em um ambiente familiar sadio a fim de que se tornassem aptos para viverem em sociedade e serem educadas nos princípios instituídos na Carta das Nações Unidas, com espírito de paz, dignidade, tolerância, liberdade, igualdade e solidariedade.

A respeito desse assunto, ressalta-se a Declaração e os Objetivos de Desenvolvimento do Milênio, adotados em setembro do ano 2000, por 189 países, na Cúpula do Milênio, na cidade de Nova Iorque. Apesar de não ter força vinculante de norma internacional, essa declaração é fundamental para o entendimento da importância da educação para crianças e adolescentes. As Nações Unidas revisaram continuamente, de forma anual, o progresso realizado para alcançar os ODMs. Por isso, com o objetivo de definir e negociar a agenda pós-2015, por ocasião da Cúpula das Nações Unidas para o Desenvolvimento Sustentável, em setembro de 2015, foi estabelecido os Objetivos de Desenvolvimento Sustentável, que orientarão as políticas nacionais e as atividades de cooperação internacional nos anos seguintes ${ }^{7}$.

No âmbito nacional, além do UNICEF ter influenciado na incorporação do Artigo 227, da Constituição Federal de 188 e na aprovação Emenda Constitucional $n^{0}$ 59, foi fundamental para a regulamentação do Estatuto da Criança e do Adolescente, instituído pela Lei $\mathrm{n}^{\circ}$ 8.069, de 13 de

\footnotetext{
${ }^{7}$ Objetivo 1. Acabar com a pobreza em todas as suas formas, em todos os lugares; 2. Acabar com a fome, alcançar a segurança alimentar e melhoria da nutrição e promover a agricultura sustentável; 3. Assegurar uma vida saudável e promover o bem-estar para todos, em todas as idades; 4. Assegurar a educação inclusiva e equitativa e de qualidade, e promover oportunidades de aprendizagem ao longo da vida para todos; 5 . Alcançar a igualdade de gênero e empoderar todas as mulheres e meninas; 6 . Assegurar a disponibilidade e gestão sustentável da água e saneamento para todos; 7. Assegurar o acesso confiável, sustentável, moderno e a preço acessível à energia para todos; 8. Promover o crescimento econômico sustentado, inclusivo e sustentável, emprego pleno e produtivo e trabalho decente para todos; 9. Construir infraestruturas resilientes, promover a industrialização inclusiva e sustentável e fomentar a inovação; 10. Reduzir a desigualdade dentro dos países e entre eles; 11. Tornar as cidades e os assentamentos humanos inclusivos, seguros, resilientes e sustentáveis; 12. Assegurar padrões de produção e de consumo sustentáveis; 13. Tomar medidas urgentes para combater a mudança do clima e seus impactos; 14. Conservação e uso sustentável dos oceanos, dos mares e dos recursos marinhos para o desenvolvimento sustentável; 15. Proteger, recuperar e promover o uso sustentável dos ecossistemas terrestres, gerir de forma sustentável as florestas, combater a desertificação, deter e reverter a degradação da terra e deter a perda de biodiversidade; 16. Promover sociedades pacíficas e inclusivas para o desenvolvimento sustentável, proporcionar o acesso à justiça para todos e construir instituições eficazes, responsáveis e inclusivas em todos os níveis; 17. Fortalecer os meios de implementação e revitalizar a parceria global para o desenvolvimento sustentável.
}

Revista Brasileira de Políticas Públicas e Internacionais, v.2, n.2, Dezembro/2017, pp. 152-167. 
SILVA, Thalita F. de M.; OLIVEIRA, Thays F. D.; CAVALCANTI, Joel M. UNICEF $e$ a implementação da Iniciativa Global Pelas Crianças Fora da Escola no Brasil

julho de 1990. Para Gandolfi (2010), as crianças e adolescentes tornam-se atores efetivos dentro da sociedade brasileira e seus direitos devem ser garantidos pela Carta Magna brasileira.

A importância do UNICEF concerne no auxílio que deu aos países para que se cumprissem, até o ano de 2015, os objetivos da Declaração e nos Objetivos de Desenvolvimento do Milênio $^{8}$. No que se refere à educação, traçou-se como objetivo garantir que, até 2015, todas as crianças terminassemos seis primeiros anos do Ensino Fundamental. Entretanto, a meta educacional do ODM não foi atingida, mesmo que avanços na área tenham sido obtidos. Por isso, o tema educacional é retomado nos Objetivos de Desenvolvimento Sustentável ${ }^{9}$.

É importante mencionar a atuação brasileira, que se fez presente em todas as sessões da negociação intergovernamental, e tem representação em diversos comitês criados para apoiar os ODS. Os avanços conquistados na área de educação no Brasil, sob influência do UNICEF, podem ser observados na implementação da Iniciativa Global Pelas Crianças Fora da Escola, que tem como objetivo alcançar a educação primária universal no Brasil, conforme meta estabelecida na Declaração e nos ODM e ODS.

\section{A Iniciativa Global Pelas Crianças Fora da Escola}

O UNICEF em parceria com o Instituto de Estatística da UNESCO (UIS) elaboraram, em 2010, uma iniciativa global intitulada Out of School Children- Pelas Crianças Fora da Escola. “A Iniciativa Pelas Crianças Fora da Escola é um aporte ao processo de análise e de ação, aberto a integrar compromissos do pensamento e de realização por parte dos governos, organismos internacionais e organizações da sociedade civil (Unicef, 2012, p. 16) ${ }^{10}$.

\footnotetext{
${ }^{8}$ 1. Erradicar a pobreza extrema e a fome; 2. Alcançar a educação primária universal; 3. Promover a igualdade de gênero e capacitar as mulheres; 4. Reduzir a mortalidade infantil; 5. Melhorar a saúde materna; 6. Combater o HIV/SIDA, a malária e outras doenças; 7. Assegurar a sustentabilidade ambienta; 8. Desenvolver uma parceria global para o desenvolvimento.

${ }^{9}$ Em seu $4^{\circ}$ objetivo, de 17, diz: “Assegurar a educação inclusiva e equitativa de qualidade, e promover oportunidades de aprendizagem ao longo da vida, para todos".

${ }^{10}$ Os países que compõe essa iniciativa são: Quirguistão, Romênia, Tadjiquistão, Turquia, Camboja, Indonésia, Filipinas, Timor-Leste, Etiópia, Moçambique, Sudão do Sul, Zâmbia, Bolívia, Brasil, Colômbia, México, Marrocos, Sudão, Bangladesh, Índia, Paquistão, Sri Lanka, República Democrática do Congo, Gana, Libéria e Nigéria.
}

Revista Brasileira de Políticas Públicas e Internacionais, v.2, n.2, Dezembro/2017, pp. 152-167. 
SILVA, Thalita F. de M.; OLIVEIRA, Thays F. D.; CAVALCANTI, Joel M. UNICEF $e$ a implementação da Iniciativa Global Pelas Crianças Fora da Escola no Brasil

Os objetivos dessa iniciativa dentre outros, são: desenvolver políticas adaptadas aos contextos específicos de cada país, para que o nível de escolaridade entre as criançasaumente em todo o mundo; diminuir as taxas de abandono de crianças na escola; estabelecer perfis detalhados das crianças excluídas da educação e identificar as barreiras que impedem as crianças de obter uma educação.

No Brasil, essa iniciativa é desenvolvida em parceria com a Campanha Nacional pelo Direito à Educação, que atua desde o ano de 1999, como rede da sociedade civil. Segundo o estudo publicado pela ONG “Todos Pela Educação” (2015) com base na Pesquisa Nacional por Amostra de Domicílio (Pnad), o Brasil possui 2.486.245 crianças e adolescentes fora da escola.

Para que os objetivos estabelecidos pela iniciativa sejam alcançados no Brasil é fundamental que a exclusão escolar seja efetivamente reduzida, o que está diretamente relacionado com a necessidade de redução das desigualdades sociais. O UNICEF (2012, p.10) acredita que:

"para continuar potencializando os avanços do país nessa área, é preciso voltar, agora, a nossa atenção para as crianças e os adolescentes que estão fora da escola ou em risco de exclusão, a maioria oriunda de populações vulneráveis, como negra, indígena, quilombola, pobre, do campo, sob risco de violência e exploração e com deficiência. É preciso, ainda, olhar para as crianças e os adolescentes que, dentro da escola, não têm garantido seu direito de aprender devido a fatores e vulnerabilidades diversos, que aumentam os riscos de abandono e evasão”.

Para garantir o direito à educação pública e de qualidade para todos, com acesso, permanência e aprendizagem das crianças e dos adolescentes, são necessárias ações conjuntas dos diferentes níveis e instâncias governamentais, com participação de variados atores (Unicef, 2012$)^{11}$. Além disso, para que os objetivos estabelecidos pela iniciativa sejam alcançados no Brasil é fundamental que a exclusão escolar seja efetivamente reduzida, o que está diretamente relacionado

\footnotetext{
${ }^{11}$ Foi criado um Grupo Gestor, sob coordenação do UNICEF e da Campanha Nacional pelo Direito à Educação, quem tem no nível internacional a participação de representantes da UNESCO e da Organização Internacional do Trabalho. No nível nacional têm-se representantes do Ministério da Educação (MEC), do Instituto Nacional de Estudos e Pesquisas Educacionais Anísio Teixeira (Inep), do Conselho Nacional de Secretários de Educação (Consed) e da Secretaria de Direitos Humanos (SDH). Além do mais, diversos dirigentes municipais foram convidados a participar do programa.
}

Revista Brasileira de Políticas Públicas e Internacionais, v.2, n.2, Dezembro/2017, pp. 152-167. 
SILVA, Thalita F. de M.; OLIVEIRA, Thays F. D.; CAVALCANTI, Joel M. UNICEF $e$ a implementação da Iniciativa Global Pelas Crianças Fora da Escola no Brasil

com a necessidade de redução das desigualdades sociais. Para tanto, esse programa diferencia quatro dimensões de exclusão, que são:

- $\quad$ Dimensão 1: Crianças em idade pré-escolar fora da escola;

- $\quad$ Dimensão 2: Crianças de 6 a 10 anos fora da escola (anos iniciais);

- $\quad$ Dimensão 3: Crianças de 11 a 14 anos fora da escola (anos finais);

- Dimensão 4: Crianças do Ensino Fundamental em risco de abandono nos anos iniciais e anos finais; ${ }^{12}$

A análise das quatro dimensões é essencial para melhor compreender as múltiplas formas de exclusão e os obstáculos para a inclusão, identificar e acompanhar de forma mais eficaz os grupos e as regiões mais vulneráveis e ampliar a articulação entre as políticas educativas e os sistemas de proteção social (Unicef, 2012). O objetivo é identificar o perfil dessas dimensões e verificar os resultados positivos e negativos com a implementação de políticas públicas educacionais, com o objetivo de garantir o acesso de todas as crianças e adolescentes em todos os níveis de ensino.

A dimensão 1 que corresponde a crianças em idade pré-escolar fora da escola, segundo dados do UNICEF (2012), em 2009, mais de 1,5 milhão de crianças não estavam matriculadas nas escolas da rede pública e privada de ensino, a maioria negros, da região Nordeste e da zona rural. Essas crianças se deparam com a falta de infraestrutura nas escolas e a dificuldade de transporte público, o que faz com que esses índices sejam maiores do que a zona urbana. As crianças entre 04 e 05 anos que se encontram fora da escola, segundo dados da Iniciativa (2015) apud Rede Brasil (2017), era de 821. 595.

A dimensão 2 que é de crianças de 06 a 10 anos, corresponde aos anos iniciais do ensino fundamental. Segundo o UNICEF (2012), no ano de 2009, mais de 375 mil crianças entre 0610 anos estavam fora da escola. Em 2015, segundo dados da Iniciativa (2015) apud Rede Brasil (2017), esse número alcançava a marca de 166.626, sendo a maioria composta por crianças e adolescentes de raça negra. negra são maioria. Carvalho (2004) menciona que o alto índice de crianças negras fora da escola pode estar relacionado à sua efetiva aprendizagem e a eventuais

\footnotetext{
${ }^{12}$ Segundo dados oficiais do Unicef são cinco dimensões, mas para efeitos de análise serão utilizados apenas quatro, resultado da aglutinação da $5^{\mathrm{a}}$ dimensão com a $4^{\mathrm{a}}$.
}

Revista Brasileira de Políticas Públicas e Internacionais, v.2, n.2, Dezembro/2017, pp. 152-167. 
SILVA, Thalita F. de M.; OLIVEIRA, Thays F. D.; CAVALCANTI, Joel M. UNICEF $e$ a implementação da Iniciativa Global Pelas Crianças Fora da Escola no Brasil

dificuldades frente ao conhecimento e ao mesmo tempo pode - ou não - ser refletido tanto nas taxas de evasão escolar e defasagem entre série e idade, quanto nos resultados em testes padronizados.

A dimensão 3 que é de crianças de 11 a 14 anos fora da escola, conforme dados do UNICEF (2012), no ano de 2009, 355.600 crianças ainda se encontravam fora da escola no Brasil. Já no ano de 2015, segundo dados da Iniciativa (2015) apud Rede Brasil (2017), essa dimensão correspondia a 220.884. Um estudo realizado por Neri (2009) revelou alguns motivos da não permanência na escola por essa faixa etária, como a dificuldade de acesso à escola, a necessidade de gerar renda para a família e a falta de interesse próprio.

A Dimensão 4 que corresponde a Crianças do Ensino Fundamental em risco de abandono (aqueles com idade superior recomendada para o ano escolar que deveriam frequentar) dos anos finais e inicias, segundo o UNICEF (2012), em 2009, encontravam-se nessa situação 3.764.437 alunos das séries iniciais do Ensino Fundamental e os anos finais do Ensino Fundamental somam $5.118 .436^{13}$. É nessa dimensão que a causa do abandono escolar assume diferentes ênfases como a deficiência do aluno (de origem médica ou psicológica), fatores intraescolares e carência cultural da criança e de suas famílias.

Como visto, a permanência na escola constitui-se ainda o maior desafio da educação escolar brasileira, pois os indicativos de exclusão ainda demonstram um quantitativo significativo de crianças e adolescentes fora da escola, que deve ser superado para que se alcance a meta 4 (assegurar a educação inclusiva e equitativa e de qualidade, e promover oportunidades de aprendizagem ao longo da vida para todos) dos Objetivos de Desenvolvimento Sustentável.

\section{Desafios à permanência da criança e do adolescente na escola}

Não se pretende aqui, apontar ou analisar as causas e as consequências do fenômeno, mas, abordar sucintamente alguns desafios relacionados à permanência da criança e do adolescente na escola. O primeira refere-se às barreiras econômicas enfrentadas pelas crianças e adolescentes. Em sua maioria, o número de crianças e adolescentes em zonas rurais é superior aos da zona urbana, o que está relacionado diretamente as barreiras econômicas vividas por esses alunos, que se depara

\footnotetext{
${ }^{13}$ Não foram achados dados mais recentes sobre essa dimensão.
}

Revista Brasileira de Políticas Públicas e Internacionais, v.2, n.2, Dezembro/2017, pp. 152-167. 
SILVA, Thalita F. de M.; OLIVEIRA, Thays F. D.; CAVALCANTI, Joel M. UNICEF $e$ a implementação da Iniciativa Global Pelas Crianças Fora da Escola no Brasil

com a necessidade de trabalhar para manter o sustento da família. Por outro lado, tem o fator do trabalho infantil.

Para Saldanha (2006), a obrigação infantil de trabalhar é maior no Nordeste, com cerca de 1/4 das crianças nordestinas trabalham e tem na pobreza o principal motivo de trabalho. Essa prática, muitas vezes é fruto da necessidade dos empregadores por mão-de-obra barata, o que acaba por gerar também, a não permanência das crianças e adolescentes na escola.

A Iniciativa Global Pelas Crianças Fora da Escola destaca que (2012) para superar essa condição no Brasil é necessário que haja o fortalecimento de programas voltados para a inclusão social e econômica de famílias abaixo da linha de pobreza. Além do mais, é fundamental que se consolide a condicionalidade de frequência na escola como parte dos programas de transferência de renda, implementando ainda, planos estaduais e municipais de erradicação do trabalho infantil.

O segundo desafio refere-se às barreiras socioculturais, isto é, a discriminação de crianças e adolescentes negros, indígenas e quilombolas. Sobre isso, Lopes (2005) discorre que essas crianças e adolescentes podem apresentar necessidades educacionais especiais, sendo necessário desenvolver ações específicas para esses grupos, que efetivem o direito à educação específica, diferenciada, intercultural, comunitária e de qualidade para todos e todas. Segundo a Iniciativa Global Pelas Crianças Fora da Escola (2012) é essencial a ampliação de programas de inclusão que contenham a discussão sobre gênero, raça e etnia, orientação sexual e religião.

A terceira barreira refere-se à oferta de educação de qualidade a todas as crianças e adolescentes. Dourado et al. (2009) afirma que é a educação de qualidade é um fenômeno complexo e abrangente que envolve diversas dimensões, não podendo ser compreendido apenas por um reconhecimento da variedade e das quantidades mínimas considerados imprescindíveis ao desenvolvimento do processo de ensino-aprendizagem, mas por uma mediação de fatores e dimensões extraescolares e intraescolares.

Por fim, destaca-se a barreira da falta de políticas públicas educacionais efetivas, que garantam a permanência das crianças e dos adolescentes na escola. As políticas públicas educacionais devem se adequar as expectativas da sociedade tendo como referência as necessidades coletivas das crianças e adolescentes. Além disso, é essencial definir programas e ações sistêmicas, integradas e conjuntas para a realização dos objetivos e metas traçadas na área da educação.

Revista Brasileira de Políticas Públicas e Internacionais, v.2, n.2, Dezembro/2017, pp. 152-167. 
SILVA, Thalita F. de M.; OLIVEIRA, Thays F. D.; CAVALCANTI, Joel M. UNICEF $e$ a implementação da Iniciativa Global Pelas Crianças Fora da Escola no Brasil

Vale mencionar ainda, que o UNICEF (2012) entende que deve ser desenvolvido políticas e programas educacionais que fortalecem a participação da sociedade civil em ações articuladas com a participação das crianças, adolescentes e suas famílias. Além do mais, é preciso a implementação de planos em todos os níveis da esfera do governo, com a gestão eficientes de metas, políticas e programas.

Nesse sentido, pode-se afirmar com base no exposto, que existem várias barreiras que dificultam a permanência das crianças e adolescentes na escola. Sendo assim, é fundamental que essas barreiras sejam diminuídas com a implementação de políticas públicas adequadas que diluam essa problemática, para que se garanta acesso total à educação por parte das crianças e dos adolescentes.

\section{Considerações Finais}

Esse artigo analisou a influência do UNICEF na construção de políticas públicas brasileiras, em especial, na implementação da Iniciativa Global Pelas Crianças Fora da Escola no Brasil, que objetiva garantir a permanência das crianças e adolescentes na escola. A participação do UNICEF ao longo dos anos tornou-se fundamental para a ampliação dos direitos à educação para as crianças e adolescentes, Além do mais, esse organismo foi essencial na implementação e no financiamento de projetos na área de educação.

Desse modo, pode-se afirmar que o UNCEF influencia positivamente para a construção e condução de políticas públicas educacionais brasileiras. Essa construção é fruto de uma necessidade global e brasileira para atender as demandas e direitos das crianças e adolescentes. Esse direito é garantido em diversos instrumentos nacionais e internacionais, com especial destaque para a Convenção das Nações Unidas sobre os Direitos da Criança (1989) e os Objetivos de Desenvolvimento Sustentável (2015).

Foram apresentados também, vários desafios que devem ser superados quanto à permanência das crianças e adolescentes na escola para que se alcance uma educação de qualidade e de acesso total a todos, independentemente da faixa etária, da raça ou da região em que more.

Revista Brasileira de Políticas Públicas e Internacionais, v.2, n.2, Dezembro/2017, pp. 152-167. 
SILVA, Thalita F. de M.; OLIVEIRA, Thays F. D.; CAVALCANTI, Joel M. UNICEF $e$ a implementação da Iniciativa Global Pelas Crianças Fora da Escola no Brasil

Por fim, espera-se que os resultados encontrados e analisados nessa pesquisa, sirvam para futuras pesquisas sobre o tema. É importante ressaltar que, o estudo dessa temática é importante para que surjam estudos na área de educação, que visem à criação de políticas públicas educacionais adequadas aos contextos específicos das crianças e adolescentes, garantindo o acesso à educação em todos os níveis de modalidade de ensino e em todas as faixas etárias.

\section{Referências}

Albernaz Júnior, V. H., \& Ferreira, P. R. V. (2011). Convenção sobre os Direitos da Criança. São Paulo: Malheiros, 2011.

Carvalho, M. P. O fracasso escolar de meninos e meninas: articulações entre gênero e cor/raça. In: Piscitelli, A., Melo, H. P., Maluf, S. W., \& Puga, V. L. (Org.). (2009). Olhares feministas. Brasília: Ministério da Educação: UNESCO.

Constituição da República Federativa do Brasil de 1988. Recuperado de http://www.planalto.gov.br/ccivil_03/Constituicao/Constituicao.htm

Dourado, L. F., Oliveira, J. F., \& Santos, C. AL. (2007). A qualidade da educação: conceitos e definições. Cad. Cedes, 29 (78): 201-215.

Fernandes, L. A., \& Gomes, J. M. M. (2003). Relatórios de pesquisa nas Ciências Sociais: características e modalidades de investigação. Contexto, 3 (4), 1-23.

Freitag, B. (1980). Escola, Estado e sociedade. 4. ed. São Paulo: Ed. Moraes.

Gandolfi, C. O Estatuto da Criança e do Adolescente, a Educação e a Escola: uma análise desta relação vinte anos após a promulgação da lei 8069. In: Oliveira, A. F., Pizzio, A., \& França, G. (2010). Fronteiras da Educação: desigualdades, tecnologias e política. PUC: Goiás.

Gil, A. C. (1991). Como elaborar projetos de pesquisa. 3. ed. São Paulo: Atlas.

Gusmão, J. B. B. (2010). Qualidade da educação no Brasil: consenso e diversidade de significados. Universidade de São Paulo, São Paulo, SP, Brasil. 2010.

Kramer, S. (2003). A política do pré-escolar no Brasil: a arte do disfarce. 7 ed. São Paulo: Cortez.

Lopes, V. N. Racismo, Preconceito e Discriminação. (2005). In: Kabengele, M. (Org.). Superando o Racismo na Escola. Brasília: MEC/SEC.

Mead, L. M. (1995). Public Policy: Vision, Potential, Limits. Policy Currents, Fevereiro:1-4.

Medeiros, L. G. (2011). A objetivação da saúde da criança pelo UNICEF: problematizando tecnologias de biopoder na Amazônia. (Dissertação de Mestrado). Universidade Federal do Pará, Belém, PA, Brasil.

Revista Brasileira de Políticas Públicas e Internacionais, v.2, n.2, Dezembro/2017, pp. 152-167. 
SILVA, Thalita F. de M.; OLIVEIRA, Thays F. D.; CAVALCANTI, Joel M. UNICEF $e$ a implementação da Iniciativa Global Pelas Crianças Fora da Escola no Brasil

Neri, M. (2009). O Tempo de Permanência na Escola e as Motivações dos Sem-Escola. Rio de Janeiro: FGV/IBRE, CPS.

Oliveira, A. F. Políticas Públicas Educacionais: conceito e contextualização numa perspectiva didática. In: Oliveira, A. F., Pizzio, A. \& França, G. (2010). Fronteiras da Educação: desigualdades, tecnologias e política. PUC: Goiás.

Peres, Claudio A., \& Castanha, André P. (2006). Educação: do liberalismo ao neoliberalismo. Revista de Educação, 1 (1), 233-238.

Rede Brasil. (2017). Unicef lança plataforma para resgatar criança que estão for a da escola. Recuperado de http://www.redebrasilatual.com.br/cidadania/2017/06/unicef-lanca-plataforma-pararesgatar-criancas-que-estao-fora-da-escola.

Richi, A. (2012). Políticas públicas educacionais e a formação do cidadão na perspectiva da educação matemática. RPEM, 1 (1), 111-130.

Saldanha, J. R. L. (2006). Trabalho Infantil e Políticas Públicas de Erradicação. Recuperado de http://monografias.brasilescola.uol.com.br/direito/trabalho-infantil-politicas-publicas-

erradicacao.htm

Santos, M. (2012, agosto). A abordagem das Políticas Públicas Educacionais para além da relação Estado e Sociedade. Anais do IX ANPED SUL - Seminário de Pesquisa em

Educação da região Sul, Caxias do Sul, Rio Grande do Sul, Brasil. Recuperado de http://www.ucs.br/etc/conferencias/index.php/anpedsul/9anpedsul/paper/viewFile/2046/147

Silva, J. P. C., \& Ramalho, R. P. (2012). Programa de Erradicação do Trabalho Infantil-PETI desenvolvido no município de Gurinhém/PB: um estudo de caso sobre o contexto socioeducativo e assistencialista. (Trabalho de Conclusão de Curso). Universidade Federal da Paraíba, João Pessoa, PB, Brasil.

Shiroma, E. O., Moraes, M. C., \& Evangelista, O. (2002). Política Educacional. 2a Ed. Rio de Janeiro: DP\&A.

Teixeira, E. C. (2002). O papel das políticas públicas no desenvolvimento local e na transformação da realidade. Cadernos da AATR -BA (Associação de Advogados de Trabalhadores Rurais no Estado da Bahia), Bahia, 3-11.

Todos Pela Educação. (2015). Brasil ainda tem 2,5 milhões de crianças e jovens fora da escola, a maioria entre 15 e 17 anos. Recuperado de http://www.todospelaeducacao.org.br/reportagenstpe/41690/brasil-ainda-tem-25-milhoes-de-criancas-e-jovens-fora-da-escola-a-maioria-entre-15-e17-anos/.

Unicef. (2012). Iniciativa Global Pelas Crianças fora da Escola. Brasília, UNICEF.

Revista Brasileira de Políticas Públicas e Internacionais, v.2, n.2, Dezembro/2017, pp. 152-167. 